\title{
ESA'S SPACEBORNE LIDAR MISSION ADM-AEOLUS; RECENT ACHIEVEMENTS AND PREPARATIONS FOR LAUNCH
}

\author{
Anne Grete Straume ${ }^{1 *}$, Anders Elfving ${ }^{1}$, Denny Wernham ${ }^{1}$, Alain Culoma ${ }^{1}$, Linda Mondin ${ }^{1}$, Frank \\ de Bruin ${ }^{1}$, Thomas Kanitz ${ }^{1}$, Dirk Schuettemeyer ${ }^{1}$, Fabio Buscaglione ${ }^{2}$, Angelika Dehn ${ }^{2}$ \\ ${ }^{1}$ European Space Agency (ESA/ESTEC), PO Box 299, 2200 AG Noordwijk, Netherlands, *Email: \\ anne.straume@esa.int \\ ${ }^{2}$ European Space Agency (ESA/ESRIN), Casella Postale 64, 00044 Frascati (Roma), Italy
}

\begin{abstract}
Within ESA's Living Planet Programme, the Atmospheric Dynamics Mission (ADM-Aeolus) was chosen as the second Earth Explorer Core mission in 1999. It shall demonstrate the potential of high spectral resolution Doppler Wind lidars for operational measurements of wind profiles and their use in Numerical Weather Prediction (NWP). Spin-off products are profiles of cloud and aerosol optical properties. ADM-Aeolus carries the novel Doppler Wind lidar instrument ALADIN.
\end{abstract}

Recently the two ALADIN laser transmitters were successfully qualified and delivered for further instrument integration. The instrument delivery will follow later this year and the satellite qualification and launch readiness is scheduled for 2016.

In February 2015, an Aeolus Science and Calibration and Validation (CAL/VAL) Workshop was held in ESA-ESRIN, Frascati, Italy, bringing industry, the user community and ESA together to prepare for the Aeolus Commissioning and Operational Phases. During the Workshop the science, instrument and product status, commissioning phase planning and the extensive number of proposals submitted in response to the Aeolus CAL/VAL call in 2014 were presented and discussed. A special session was dedicated to the Aeolus CAL/VAL Implementation Plan.

In this paper, the Aeolus mission, status and launch preparation activities are described.

\section{BACKGROUND AND MOTIVATON}

The European Space Agency's (ESA's) Living Planet Programme includes two types of complementary user driven missions: the research oriented Earth Explorer missions and the operational service oriented Earth Watch missions. Earth Explorer missions are divided into (i) Core missions being larger missions demonstrating the capabilities of new technologies addressing issues of wide scientific interest, and (ii) Opportunity missions with a similar scope but being smaller in terms of cost to ESA. Both types of missions address the research objectives set out in the Living Planet Programme document [1]. All Earth Explorer missions are proposed, defined, evaluated and recommended by the scientific community. ADM-Aeolus was selected as the second Earth Explorer Core mission in 1999, and sets out to demonstrate the potential of space-borne Doppler Wind lidars for operational use.

\section{ADM-AEOLUS MISSION}

\subsection{Background and objectives}

The motivation for the selection of the Aeolus mission was the need for more abundant direct wind profile measurements in the current Global Observing System (GOS), which is used e.g. by NWP and climate models [2]. In the current GOS, direct wind profile measurements are obtained from radiosondes, commercial aircraft ascends and descends and ground-based wind lidars and radars. The distribution of these measurements is, however, not homogenous, with most observations taken over land in the Northern Hemisphere. Winds can also be inferred from temperature soundings when the flow is in geostrophic balance, which is only the case for large-scale wind fields in the extra-tropics. AirMotion-Vectors deduced from cloud-tracking is limited by the difficulty in performing accurate height-assignments. It is therefore expected that the Aeolus mission will largely contribute to the 
improvement of predictions of small-scales flows and forecasts in observation-sparse regions.

The current lack of homogenous sampling of the 3-dimensional wind field in large parts of the tropics and over the major oceans leads to difficulties in the studying of key processes in coupled climate systems and further improvements of NWP. Aeolus measurements are expected to improve short-range forecasts of severe weather and modelling of tropical dynamics in particular. Recommendations from the scientific and NWP community lead to the selection of the Aeolus space-based lidar in 1999.

\subsection{Instrument concept}

Aeolus will embark the direct detection Doppler Wind Lidar instrument ALADIN (Atmospheric LAser Doppler INstrument). ALADIN is a pulsed UV lidar $(355 \mathrm{~nm}$, circularly polarized, $50 \mathrm{~Hz})$, measuring continuously along the orbit (Figure 1, left panel). Its high spectral resolution concept allows for the detection of the parallel polarized molecular (Rayleigh) and particle (Mie) backscattered signals in two separate channels, each sampling the wind in 24 vertical height bins (Figure 1, right panel). This makes it possible to deliver winds both in clear and (partly) cloudy conditions down to optically thick clouds. The height of the wind measurement is detected by time-gating. A quasi-global coverage is achieved daily ( 15 orbits per day) and the orbit repeat cycle is 7 days (109 orbits). The orbit is sunsynchronous with a local equatorial crossing-time of $6 \mathrm{am} / \mathrm{pm}$. A detailed description of the instrument design and operation can be found in [3]. A demonstration of the measurement concept can be found in e.g. [4].

\subsection{Products and product requirements}

The main product from ADM-Aeolus will be horizontally projected line-of-sight (HLOS) wind profile observations (approximately zonally oriented) from the surface up to about $30 \mathrm{~km} \mathrm{[3].}$ The atmospheric backscattered signal for the individual laser pulses are averaged on-board to yield $\sim 3 \mathrm{~km}$ measurements. These measurements are further averaged on-ground to observations, representing horizontal averaging on a $\sim 87 \mathrm{~km}$ scale. The vertical resolution of the layer-average winds vary from 0.25 to $2 \mathrm{~km}$, and can be adapted

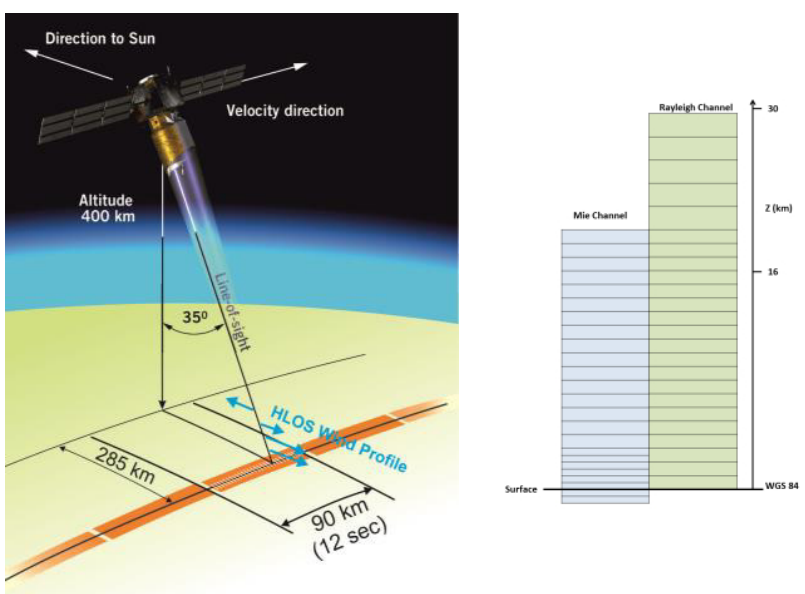

Figure 1: The Aeolus orbit, pointing and sampling characteristics (left) and an example of the vertical measurement binning (right).

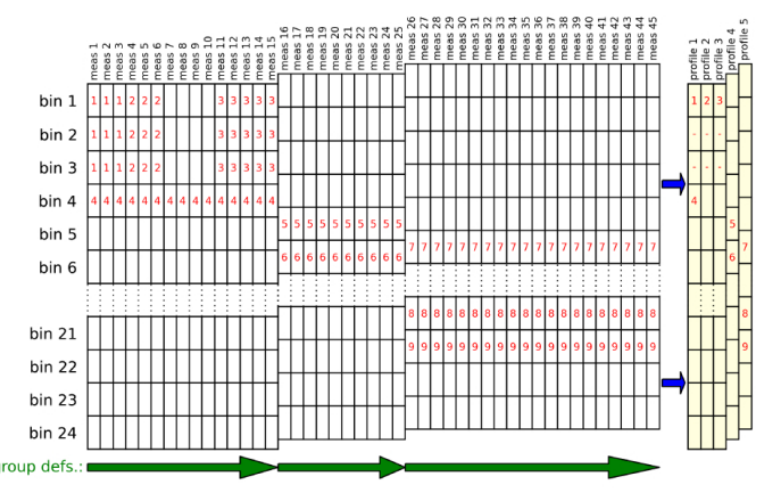

Figure 2: Schematic view of the Aeolus L2b wind observation processing. The number indicate different scene classifications (clouds versus no clouds), resulting in a number of wind profiles for an observation. These are partial or full wind profiles for the Rayleigh (cloud free) and Mie (cloud or aerosol layer winds) channels. Courtesy J. De Kloe (KNMI).

as a function of the under-laying topography and/or climate zone. The required wind accuracies are $2 \mathrm{~m} / \mathrm{s}$ in the planetary boundary layer (PBL), $2-3 \mathrm{~m} / \mathrm{s}$ in the free troposphere, and $3-5 \mathrm{~m} / \mathrm{s}$ in the stratosphere. The wind profiles are classified into cloudy and cloud free profiles, as illustrated in Figure 2. A detailed description of the Aeolus wind profile retrievals can be found in [5].

ADM-Aeolus will also deliver height profiles of Mie and Rayleigh co-polarized backscatter and extinction coefficients, scattering ratios and lidar ratios [6] along the lidar line-of-sight. From these parameters it is possible to derive cloud and aerosol information such as layer height, multi- 
layer cloud and aerosol stratification, cloud and aerosol optical depths (integrated light-extinction profiles), and some information on cloud/aerosol type (lidar ratio).

\subsection{Science activities in support of the user requirements and in-flight operation}

During the technical development of the ALADIN laser, changes to the instrument operation strategy had to be implemented in order to meet the strict user requirements on stability and measurement accuracy. The initial strategy was to operate the instrument in so-called burst mode, where the instrument was operated at $100 \mathrm{~Hz}$ during $50 \mathrm{~km}$ and then switched off for $150 \mathrm{~km}$, once every 200 $\mathrm{km}$. The $200 \mathrm{~km}$ observation spacing assured an uncorrelated sampling scheme. A new strategy was introduced in 2010, operating the instrument in so-called continuously pulsed mode, i.e. continuous sampling along the orbit. Due to laser life-time issues and electrical power limitations, the pulse repetition frequency was reduced to 50 $\mathrm{Hz}$ which meant that the horizontal observation averaging had to be increased from $50 \mathrm{~km}$ to $\sim 100$ $\mathrm{km}$ to obtain sufficient SNR.

This change in the Aeolus sampling led to changes in the spatial representativity of the observations, and the Aeolus mission requirements had to be revisited to investigate whether the spatial sampling requirements could be relaxed. As a result, impact studies [7-8] were initiated to consolidate and optimize the onground data processing for maximum NWP impact. The studies addressed the role of NWP model background error correlations, measurement representativeness errors, and an optimized measurement processing strategy to maximize mission impact. The studies concluded that the current operational version of the ECMWF model represents the atmospheric variability well, down to horizontal scales of about $100 \mathrm{~km}$ (the so-called effective model resolution). Since the Aeolus observation sizes are now $\sim 100 \mathrm{~km}$, the associated observation representativeness error in the current ECMWF model would be small because the observation length is comparable to the effective model resolution. This confirmed that the current $100 \mathrm{~km}$ horizontal averaging strategy. The studies furthermore showed that horizontally projected line-of-sight wind profiles significantly improves
ECMWF forecasts in the upper troposphere and in the tropics, and that unknown biases must be kept small and well below $1 \mathrm{~m} / \mathrm{s}$. Especially rangedependent biases are found to be detrimental for NWP. The impact is comparable to the impact of the present radiosonde network. Further recommendations to the sampling strategy were also given.

\subsection{Aeolus Mission status}

During the Aeolus development phase, a number of technical challenges for the Aeolus system have appeared and have been tackled. These include laser diode performance, optical mounting stability, laser induced damage on the IR and UV coatings, laser-induced contamination in vacuum, and long-term UV energy drift. The transmit lasers and optical bench assembly have been extensively retrofitted and tested, and the Aeolus transmit lasers are at the time of writing being integrated in the ALADIN instrument. The instrument delivery is scheduled for end 2015 and satellite qualification and launch readiness for end 2016. The satellite platform was ready in 2009 and has since then been in storage. The satellite Assembly, Integration and Testing teams are being reactivated. The mission Payload Data Ground Segment and Flight Operations Segment teams have also been reactivated and are preparing and running the final overall validation testing in preparation for launch. The ESA and industrial in-orbit Commissioning planning is under review and finalization.

\subsection{Aeolus CAL/VAL preparations}

An Announcement of Opportunity (AO) call for CAL/VAL support studies for Aeolus took place in 2007. The AO was a call for validation of the Aeolus wind and optical properties products during its commissioning and successive 3-year exploitation phase. Sixteen proposals including ground-based and airborne validation experiments were received from teams all around the globe, whereof fifteen successfully passed the review. Due to the delays of the Aeolus programme and the recent changes to the Aeolus operation, a delta-call was released in May 2014. The main objectives of the delta-call was (i) to allow confirmation of the fifteen CAL/VAL proposals from the 2007 call and (ii) to call for new proposals. In total 17 proposals were received in 
response of the delta-call, whereof 2 were joint national proposals and 3 included a number of institutes both national and international. Most of the proposals proposed validation of both the wind and aerosol/cloud products. Activities of special interest included tropical stratospheric balloon experiments and the inclusion of collocated measurements in polar areas. All proposals were accepted.

A Science and CAL/VAL workshop was held in ESA_ESRIN in February 2015 (http://www.aeolus-science-calval-2015.org/).

The workshop brought industry, the user community and ESA together to prepare for the Aeolus Commissioning Phase and beyond. During the Workshop presentations of the science, instrument and product status, Commissioning phase planning and the extensive number of proposals submitted in response to the Aeolus CAL/VAL call in 2014 were given. Furthermore, the Aeolus CAL/VAL Implementation Plan was drafted in a plenary session. The workshop allowed the teams to start activity coordination and exchange of information.

A pre-launch campaign with the ALADIN Airborne Demonstrator (A2D) and other wind lidar instrumentation from DLR and NASA in May 2015 will, furthermore, allow for CAL/VAL rehearsal and testing of the ALADIN on-ground data processing algorithms.

\section{CONCLUSIONS}

With the recent start of the ALADIN instrument integration and delivery in 2015, the Aeolus Mission is nearing its completion for launch. ESA, industry and the scientific community is getting prepared for Commissioning phase, $\mathrm{CAL} / \mathrm{VAL}$ and product exploitation.

\section{REFERENCES}

[1] European Space Agency, (1998) The Science and Research Elements of ESA's Living Planet Programme. ESA SP-1227, 105 pp.

[2] World Meteorological Organisation (WMO) (2004) Proc. of the 'Third WMO Workshop on the Impact of various observing systems on Numerical Weather Prediction'. WMO/TD No. 1228, 329 pp.
[3] European Space Agency, (2008) ADM-Aeolus Science Report. ESA SP-1311, 121 pp.

[4] Marksteiner, U., Airborne Lidar Observations for the validation of the ADM-Aeolus instrument, $\mathrm{PhD}$ Thesis and the Technical University of Munich, http://mediatum.ub.tum.de/doc/1136781/ 1136781.pdf.

[5] Tan, D. G. H. et al., (2008) The ADM-Aeolus wind retrieval algorithms. Tellus, 60A, pp. 191205.

[6] Flamant, P. et al., (2008) ADM-Aeolus retrieval algorithms for aerosol and cloud products. Tellus, 60A, pp. 273-286.

[7] Horanyi, A. et al. (2014) The assimilation of horizontal line-of-sight wind information into the ECMWF data assimilation and forecasting system, Part I: The assessment of wind impact, Q. J. R. Meteorol. Soc. (2014) DOI:10.1002/qj.2430.

[8] Marseille, G.-J., et al. (2013), Final Report Vertical and Horizontal Aeolus Measurement Positioning, CCN2 to ESA contract 20940, http://www.knmi.nl/ marseill/publications/fulltex ts/AE_FR_VHAMP_v1.0.pdf. 